\title{
Effects of Relative Deprivation on Intention to Rebel: A Multiple Mediation Model
}

\author{
Xiang-Yu Chen, ${ }^{*}$ Xin-Qiang Wang, ${ }^{*}$ Jian-Ping Liu, Sheng-Hong Dong, Jun-Cheng Zhu, and \\ Jun-Yu Huo \\ School of Psychology, Center for Mental Health Education and Research, Jiangxi Key Laboratory of Psychology and Cognition \\ Science, Jiangxi Normal University, Nanchang, China.
}

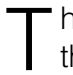
his study examined the mediating effects of future social expectations and interpersonal distrust on the relationship between individual relative deprivation and intention to rebel. Data were gathered from 807 people from multiple occupational backgrounds in a municipality in southwest China. Structural equation modelling showed that individual relative deprivation predicted intention to rebel directly and also that it predicted intention to rebel indirectly via negative future social expectations, interpersonal distrust, and a chain mediating effect of negative future social expectations and interpersonal distrust. These results highlight the importance of the associations between future social expectations and interpersonal distrust with intention to rebel in people who report relative deprivation. The findings also indicate that prevention and intervention programs related to relative deprivation and intention to rebel in China are worthy of further research.
\end{abstract}

Keywords: collective behaviour, future social expectations, intention to rebel, interpersonal distrust, relative deprivation

Rulers of states and chiefs of families are not concerned lest their people should be poor, but only lest what they have should be ill-proportioned.

\section{Confucian Analects Book XVI: Ke She}

In 1978, the Chinese government launched an extensive reform program to reduce poverty and liberalise the economic market. Since then, China has shown extraordinary achievements in economic development and improvements in public services. However, while living and cultural standards have improved, the gap between rich and poor people has expanded. According to data from the National Bureau of Statistics, China's Gini coefficient, a measure of economic inequality, fluctuated around 0.46 between 2003 and 2016, which is above the warning line (i.e., 0.4). A growing body of evidence and theory suggests that many negative social and health outcomes, including violence, conflict, suicide, drug abuse, overweight, lack of trust, and mental disease are associated with income inequality (Rowlingson, 2011; Rözer \& Volker, 2016; Wilkinson \& Pickett, 2007, 2009). Why are rates of happiness falling in a growing economy? Psychologists and sociologists have used the concept of relative deprivation
(RD) to explain the phenomenon (Brockmann, Delhey, Welzel, \& Yuan, 2009; Mishra \& Novakowski, 2016).

\section{Relative Deprivation}

Stouffer, Suchman, Devinney, Star, and Williams (1949), from the Research Division of the Information Branch of the U.S. Army, coined the term 'relative deprivation' in their classic study, The American Soldier. RD, a key consequence of inequality, involves subjective feelings of anger, resentment, and frustration in response to negative social comparisons with relevant others (Bernstein \& Crosby, 1980; Smith, Pettigrew, Pippin, \& Bialosiewicz, 2012). That is, individuals experience feelings of wanting, deserving, and resentment for not having what others have (Smith et al., 2012; Sun \& Guo, 2016). This inner feeling of comparative disadvantage stems from individual or intergroup comparison rather than absolute disadvantage (Smith et al., 2012). As seen in the epigraph above, Confucius said, '[be] not concerned lest ... people should be poor, but only lest what they have should be ill-proportioned', an insight that reflects the essence of RD (Xiong \& Ye, 2016).

Address for correspondence: Xin-Qiang Wang, School of Psychology, Jiangxi Normal University, No 99, Ziyang Road, Nanchang, Jiangxi Province, 330022, China.Email: xinqiangw101@163.com

*These authors contributed equally to this work and should be considered co-first authors. 
$\mathrm{RD}$ can be divided into egoistic or individual $\mathrm{RD}$ (IRD) and fraternal or group RD (GRD); the former involves interpersonal comparisons, while the latter involves intergroup comparisons (Runciman, 1966; Smith et al., 2012). In an extensive study of British society, Runciman (1966) found that his respondents tended to make interpersonal comparisons that produced IRD, rather than broad social comparisons between their group and other groups. It can be seen that the focus of most previous studies on the consequences of IRD was put on internal states and individually oriented behaviour (Smith et al., 2012). However, we contend that as an outcome of interpersonal comparisons, IRD should also have significant interpersonal implications and even intergroup implications. Besides, given that some previous studies have shown that GRD is an incentive for intergroup attitudes and collective behaviour (Toizer, 2016; Zhang, Wang, \& Zhou, 2010), and the two types of RD are significantly correlated (Guimond \& Dubésimard, 1983), unique longitudinal effects of GRD and IRD on both wellbeing and protest have been identified (Schmitt, Maes, \& Widaman, 2010). Hence, it is reasonable to expect that IRD may influence individuals' perceptions of social and interpersonal relationships, as well as their intention to fight and/or resulting violent actions. However, little research has investigated the relationship between IRD and collective behaviours in Chinese people. Therefore, it is important to clarify the relationship between IRD and intention to rebel in Chinese people during the reform era, to elucidate the relationships between variables that affect collective behaviour. This is of great theoretical value, as well as having far-reaching, practical significance for maintaining social stability and promoting the construction of a harmonious society.

\section{Intention to Rebel}

Rebellion refers to the act of defying lawful authority or relating to authority or convention in a resistant manner (Mathye, 2009). It is characterised by a response to frustration with the community and new values, which often leads to an ideological 'revolution' (Kurzman, 2003; Vold, Bernard, \& Snipes, 2005). A growing body of evidence and theory have associated rebellion with violent conflict, antisocial behaviour, and collective behaviour (Gurr, 1970; Jost et al., 2012; Offer, 1971; Pires, 2014). Social anomie theory posits that rebellion is an important cause of mass crime (Ma, 2012; Merton, 1949; Shoham, Knepper, \& Kett, 2010; Vold et al., 2005). However, examination of any effect of IRD on collective behaviour has not yet provided a unified conclusion. Some research has tried to relate IRD to protest movements (Pettigrew, 1978; Schmitt et al., 2010; Vanneman \& Pettigrew, 1972; Zhang, Liu, \& Tian, 2016). In Why Men Rebel, Gurr (1970) explained rebellious behaviour using relative derivative theory and frustration-aggression theory. Gurr posited that IRD, defined as the discrepancy between value expectations and value capabilities, induces frustration and social discontent, which may in turn lead to widespread negative emotions, which then may trigger collective and political violence (Folger, 1986; Gurr, 1970; Napoletano, Elgar, Saul, Dirks, \& Craig, 2016). Moreover, Crosby (1979) claimed that IRD can lead to 'violence against society' and 'constructive change of society', and sometimes this can be as violent as a riot (Crosby, 1979; Smith et al., 2012). Crosby (1979) also argued that rebellion should be viewed as an extreme example of violence. In addition, just as Schmitt et al. (2010) argued that IRD will produce rebellion instead of or in addition to aggressive behaviour, we contend that the experience of IRD may be inherently compatible with rebellious behaviours.

However, researchers are not permitted to simulate rebellion for moral and ethical reasons. According to the theory of planned behaviour (Ajzen, 1985), behavioural intention is the factor that affects behaviour most directly. Therefore, this study researched the intention to rebel rather than rebellious behaviour.

\section{Future Social Expectations}

Individuals who experience RD respond in different ways (Osborne, Smith, \& Huo, 2012), such as raising their own status through hard work (Zoogah, 2010), changing the reference group to reduce their $\mathrm{RD}$, or disrupting the group's status quo (Sun \& Guo, 2016). Which factors mediate the relationship between IRD and intention to rebel? Smith and Huo (2014) suggested that people's responses to $\mathrm{RD}$ depend on an estimate of the possibility of amelioration. That is, if people believe that there is an opportunity for change (i.e., in an open system), they are likely to respond, even to an undeserved disadvantage, with increased normative effort. However, if there is no such opportunity available (in a closed system), they are likely to engage in deviant or confrontational behaviour. In this respect, future social expectation is a mediator variable worth considering. According to Atkinson and Cartwright's (1964) theory of expectancy value and Nurmi's (1991) theory of future orientation, future social expectation is defined as an individual's estimate of the future development of society and living environments, based on the reality of the current situation. Although there is no direct evidence linking IRD to future social expectation, considerable circumstantial evidence lends support to the idea that IRD is positively associated with negative future social expectation and negatively associated with positive future social expectation. A previous study has shown that underemployment generates the feeling of IRD, and that IRD in turn adversely affects individuals' attitudes toward their future careers more generally (Feldman, Leana, \& Bolino, 2002). IRD has also been shown to predict negative attitudes toward the social systems (Birt \& Dion, 1987; Caskell \& Smith, 1984; Smith \& Huo, 2014). Furthermore, some studies indicate that the experience of IRD poses a threat to individuals' belief in a just world (BJW) (Callan, Shead, \& Olson, 2011; Zhang et al., 2016). BJW is the belief that 
people live in a just world where each person usually gets what they deserve (Lerner \& Miller, 1978); the stronger the BJW, the more confident and the more positive the person's estimation about the future (Sutton \& Winnard, 2007). From this perspective, we suggest that IRD should also be associated with one's attitudes toward future society. In addition, laboratory participants' feelings of hope for improved conditions in the future have been shown to predict their collective reactions to RD (Wright, Taylor, \& Moghaddam, 1990). Moreover, individuals with positive expectations of the future have been shown to be less likely to exhibit drug abuse, alcoholism, suicide, antisocial behaviour, and confrontational tendencies (Carmi \& Arnon, 2014; Cohen-Chen, Halperin, Crisp, \& Gross, 2013; Nurmi, 1991; Uslaner, 2002); in contrast, when individuals believe that the future will involve difficulty and threat, they are likely to rebel rather than exhibit positive behaviour (Bar-Tal, Raviv, Shapira, \& Kahn, 2016; CohenChen et al., 2013).

\section{Interpersonal Distrust}

Trust is one of the Five Constant Virtues of Confucianism (the others are Benevolence, Righteousness, Propriety, and Wisdom), which are the most important virtues in Chinese tradition and exert a significant influence on the psychology and behaviour of Chinese people. Trust is applied in predicting individual cooperative behaviour and compliance with the overall rules of society (Coleman, 1990; Fukuyama, 1995; Paxton, 2002; Scholz \& Lubell, 1998; Sztompka, 1999; Tatarko, 2014; Uslaner, 2002; van Lange, 2006). In contemporary society, the distrust crisis has led to several issues such as the 'credibility trap', tension between doctors and patients, and poor food safety (Kasperson, Golding, \& Tuler, 1992; Zhang, Guo, \& Zhang, 2013); however, very few studies have included distrust as a variable. Therefore, it is important to explore the relationships between interpersonal distrust and IRD, intention to rebel, and future social expectations.

Social psychology posits that income inequality affects levels of trust via subjective injustice (Alesina \& Ferarra, 2002; Brockner \& Siegel, 1996; Uslaner, 2002). Severe income inequality increases RD levels in low-income earners (Neckerman \& Torche, 2007; Ishida, 2014; Greitemeyer \& Sagioglou, 2017), making them more likely to refuse to trust society and other people (Uslaner, 2010). Experimental and theoretical studies have also shown that RD exerts a strong depressive influence on trustworthiness (Anderson, Mellor, \& Milyo, 2005; Wilkinson \& Pickett, 2007, 2009). In addition, the occurrence of collective rebellious behaviour throughout history has almost always been related to lack of trust, which is one of the most important factors in controlling intergroup conflict. Some studies have shown that interpersonal trust is significantly negatively correlated with aggressive behaviour (Catherall, 1991; Kinard, 1980, 1982; Malti, Averdijk, Ribeaud, Rotenberg, \& Eisner, 2013). Furthermore, Giddens (1984) posited that human life requires a sense of security and trust, and that when distrust deepens, the anxiety and anger it causes leads to violence.

Interpersonal distrust refers to individuals' expectations of incapability, negative emotion, and harmful behaviour from others (Cho, 2006; Rotter, 1971; Schweer \& Siebertz-Reckzeh, 2014; Zhang \& Bond, 1993). The classical cognitive model of interpersonal trust posits that greater expectation of feedback is associated with a stronger sense of trust (Zhang \& Bond, 1993). Furthermore, Uslaner $(2010,2013)$ reported that optimism affects individuals' trust and distrust of strangers; that is, positive expectations of the future serve as the foundation of interpersonal trust (Teng, Jin, \& Liu, 2016; Uslaner, 2010, 2013). Therefore, it is reasonable to assume that negative expectations of the future increase interpersonal distrust, while positive future social expectations will reduce it.

\section{Overview of the Current Study}

This study sought to extend the findings of previous research in several ways. First, we recruited a diverse Chinese community sample to maximise variability in IRD and intention to rebel. In addition, we chose to measure IRD specifically because previous research has considered group relative deprivation, rather than IRD, as a predictive factor for collective behaviour. Moreover, many previous studies that have examined the relationship between IRD and collective behaviour have done so only from a theoretical perspective or by conducting separate studies. Therefore, based on theoretical analysis, this study included two novel variables - future social expectations and interpersonal distrust - to enhance current understanding of the relationship between them.

The first hypothesis was that IRD would be a positive predictor of intention to rebel. The second hypothesis was that positive and negative future social expectations would affect the relationship between IRD and intention to rebel. The third hypothesis was that interpersonal distrust would play a mediating role in the relationship between IRD and intention to rebel. The fourth hypothesis was that IRD would affect interpersonal distrust via the two types of future social expectations and subsequently affect intention to rebel.

\section{Method \\ Participants}

We adopted a stratified random sampling strategy to recruit participants older than 18 years from a municipality in southwest China, and a unified testing method was implemented. The questionnaire was completed anonymously and returned to the researchers immediately following completion. A total of 1,000 questionnaires were distributed, and 807 valid questionnaires were returned. Of the 807 participants, $51.8 \%$ were women. They represented diverse occupational backgrounds including administrators in the modern state and society 
(3.9\%); business managers (4.2\%); private entrepreneurs (3.4\%); professional technicians (9.4\%); staff from party and governmental offices, companies, and institutions (23.4\%); individual industrial and commercial workers (8.3\%); business service personnel (6.6\%); manual workers (2.2\%); farmers (5.1\%); full-time students (20.8\%); unemployed people (2.7\%); freelancers $(4.8 \%)$; and others $(5.2 \%)$. The proportions of participants aged $17-25,26-35,36-45,46-55$, and $>56$ years were $28.0 \%$, $30.8 \%, 24.7 \%, 12.9 \%$, and $1.5 \%$ respectively, while the ages of $2.1 \%$ of participants were not provided. With respect to educational levels, $7.9 \%, 17.5 \%, 22.9 \%, 43.5 \%$, $7.3 \%$, and $0.4 \%$ of participants were educated to junior high school level or below, high school/special secondary school level, college level, university level, master's degree level, and doctorate level respectively, and $0.5 \%$ of participants did not provide this information.

\section{Measures}

We developed a general information questionnaire to collect data regarding demographic characteristics such as sex, age, educational level, and occupation.

IRD. IRD was assessed using the Individual Relative Deprivation Scale (Ma, 2012), which consists of four items that measure the degree to which people experience RD. Responses are provided using a Likert-type scale ranging from 1 (strongly disagree) to 6 (strongly agree); higher scores indicate a stronger sense of RD. The scale items include 'With the effort I make and my pay, my life should be better than it is now'; 'I always feel that others take the things that belong to me'; 'Compared with the people around me, I am at a disadvantage both in life and at work'; and 'Most of the wealthy people in the community rely on disgraceful means to make a fortune and steal my opportunities'. Cronbach's alpha for the scale was .79 in the current study.

Future social expectations. A four-item scale developed by $\mathrm{Ma}$ (2012) was used to measure attitudes toward future social issues or future social expectations. Responses are provided using a Likert-type scale ranging from 1 (strongly disagree) to 6 (strongly agree). The scale consists of two subscales. The first was Positive Future Social Expectations, whose items were 'Society is always moving forward in time, and I believe life will get better and better' and 'I have full confidence in the future of China'; these two items were combined into an overall index of positive future social expectations, $r=.67, p<.01$. For the second, Negative Future Social Expectations, items were 'To tell the truth, I think China's future social problems will be more and more difficult to solve' and 'Most people are not optimistic about the future of China'; these two items were combined into an index of negative future social expectations, $r=.64, p<.01$.

Interpersonal distrust. A three-item scale developed by $\mathrm{Ma}$ (2012) was used to measure interpersonal distrust. Responses are provided using a Likert-type scale ranging from 1 (strongly disagree) to 6 (strongly agree), in which higher scores indicate stronger interpersonal distrust. The scale items were 'People take advantage of each other; if you don't be careful, you'll suffer losses'; 'People do more and more hypocritical things in our society'; and 'Even the closest person can't be trusted in the current society'. Cronbach's alpha for the scale was .64 in the current study.

Intention to rebel. A six-item scale developed by $\mathrm{Ma}$ (2012) was used to measure intention to rebel. Responses are provided using a Likert-type scale ranging from 1 (strongly disagree) to 6 (strongly agree), in which higher scores indicate stronger intention to rebel. The scale items include 'I would use violence against corrupt officials as long as someone else did so first', 'In this society, people need blood for blood and tit for tat and are not soft', 'The laws that are beneficial only to rich and powerful people can be broken', 'The only means of attracting attention to the legitimate rights and interests of ordinary people are strikes or sit-downs', 'In today's society, use of illegal means to achieve goals is unavoidable', and 'Chinese people can't solve their current problems just on their own and need foreign forces and ideas'. Cronbach's alpha for the scale was .77 in the current study.

\section{Data Analysis}

The statistical analyses were performed using SPSS 20.0, AMOS 17.0, and MPLUS 7.0. SPSS 20.0 was used to analyse descriptive statistics and perform correlations, AMOS 17.0 was used to perform structural equation modeling, and MPLUS 7.0 was used to assess multiple mediating effects with 1,000 bootstrap samples. We developed and assessed structural equation models based on the hypotheses and determined the extent to which they fit the data. We used the maximum likelihood method with the following fit indices: $\chi^{2}$, root-mean-square error of approximation (RMSEA), comparative fit index (CFI), normative fit index (NFI), incremental fit index (IFI), Tucker-Lewis index (TLI), root-mean-square residual (RMR), and adjusted goodness-of-fit index (AGFI). Recent statistical research has demonstrated the importance of examining indirect effects separately, given that an overall total effect is unnecessary for the occurrence of mediation (MacKinnon, 2000; Preacher \& Hayes, 2008; Shrout \& Bolger, 2002). Bootstrapped confidence intervals are currently considered the best method for the assessment of mediation. In assessing indirect effects, 95\% bias-corrected and accelerated bootstrap confidence intervals that do not include zero indicate significant mediation. In the current study, a random sample was used to extract 1,000 bootstrap samples from the original data $(N=807)$.

\section{Results}

\section{Correlation Analysis}

The mean scores for IRD, positive future expectations, negative future expectations, interpersonal distrust, and intention to rebel were $3.42(S D=0.88$, range $1.00-6.00)$, 


\section{Table 1}

Zero-Order Correlations Between Individual Relative Deprivation, Future Social Expectations, Interpersonal Distrust, and Intention to Rebel

\begin{tabular}{lrlll}
\hline Variables & 1 & 2 & 3 & 4 \\
\hline 1. Individual relative deprivation & & & & \\
2. Positive future social expectations & $-.184^{* * *}$ & & & \\
3. Negative future social expectations & $.584^{* * *}$ & $-.170^{* * *}$ & & \\
4. Interpersonal distrust & $.648^{* * *}$ & $-.112^{* * *}$ & $.581^{* * *}$ & \\
5. Intention to rebel & $.696^{* * *}$ & $-.191^{* * *}$ & $.644^{* * *}$ & $.641^{* * *}$ \\
\hline
\end{tabular}

Note: $N=807$

*** $p<.001$.

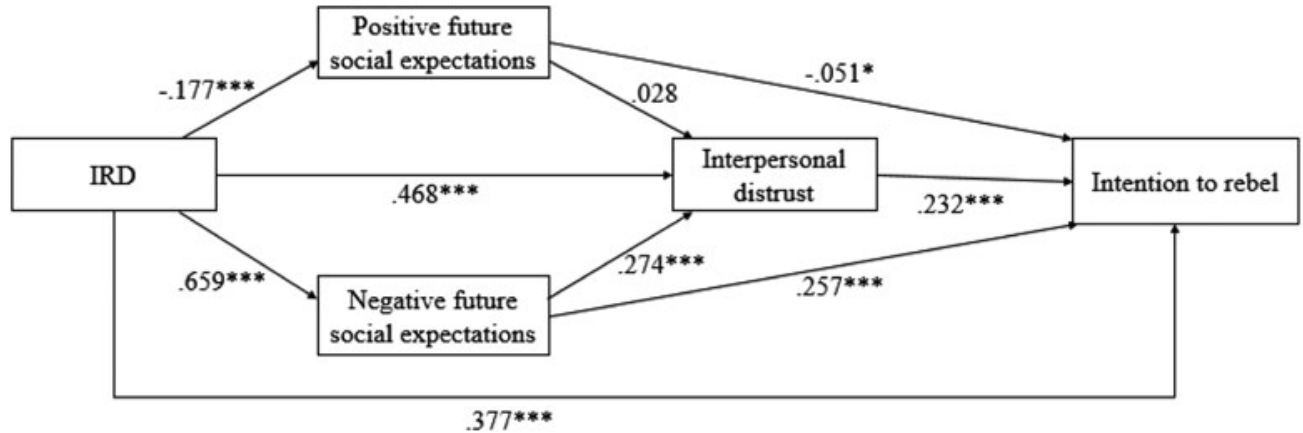

\section{Figure 1}

Structural equation model of the effects of individual relative deprivation, future social expectations, and interpersonal distrust on intention to rebel. Note: IRD = individual relative deprivation. ${ }^{*} p<.05,{ }^{* * *} p<.001$.

$4.47(S D=0.84$, range 1.00-6.00), $3.61(S D=0.99$, range $1.00-6.00), 3.61(S D=0.87$, range $1.00-6.00)$, and 3.34 $(S D=0.89$, range $1.00-5.83)$ respectively; Table 1 shows the correlations between these variables, which were significant. Specifically, IRD was significantly positively correlated with negative future social expectations, interpersonal distrust, and intention to rebel ( $r \mathrm{~s}=.58$ to .70 ) and significantly negatively correlated with positive future social expectations $(r=-.18)$; positive future social expectations were significantly negatively correlated with negative future social expectations, interpersonal distrust, and intention to rebel $(r s=-.11$ to -.19$)$; negative future social expectations were significantly positively correlated with interpersonal distrust and intention to rebel $(r=.58$ to .64); and interpersonal distrust was significantly positively correlated with intention to rebel $(r=.64)$.

\section{Development and Analysis of Structural Equation Models}

The final structural equation model is shown in Figure 1. The results regarding goodness of fit were as follows: $\chi^{2}(1$, $807)=4.89, \mathrm{RMSEA}=.07, \mathrm{CFI}=.99, \mathrm{NFI}=.99, \mathrm{IFI}=.99$, $\mathrm{TLI}=.98, \mathrm{RMR}=.01$, and AGFI $=.96$. These values were all well within recommended levels, indicating that the model was acceptable.

\section{Significance of Mediating Effects}

As shown in Table 2, negative future social expectations exerted a mediating effect on the relationship between IRD and intention to rebel $(\beta=.17, p<.001)$. In addition, the mediating effect of interpersonal distrust on the relationship between IRD and intention to rebel was significant $(\beta=.11, p<.001)$. IRD affected interpersonal distrust via negative future social expectations and subsequently affected intention to rebel; therefore, negative future social expectations and interpersonal distrust exerted multiple mediating effects on the relationship between IRD and intention to rebel $(\beta=.04, p<.001)$. The mediating effect of positive future social expectations on the relationship between IRD and intention to rebel was marginally significant $(\beta=.01, p=.062)$. The multiple mediating effects of positive future social expectations and interpersonal distrust on the relationship between IRD and intention to rebel were non-significant $(p=.362)$.

\section{Discussion}

This study examined the mechanisms underlying the association of IRD with intention to rebel. The results showed that IRD exerted a positive effect on intention to rebel, which supported the first hypothesis. In addition, negative future social expectations exerted a mediating effect between IRD and intention to rebel, and the mediating effect of positive future social expectations was marginally significant, which provided partial support for the second hypothesis. Further, interpersonal distrust played a mediating role in the relationship between IRD and intention to rebel, which supported the third hypothesis. Moreover, RD affected interpersonal distrust via negative future social expectations and subsequently influenced the intention to rebel; however, positive future social expectations and interpersonal distrust did not 
Table 2

Indirect Effects Based on 1,000 Bootstrapped Samples

\begin{tabular}{|c|c|c|c|c|}
\hline \multirow[b]{2}{*}{ Paths } & \multirow[b]{2}{*}{ Indirect effects } & \multirow[b]{2}{*}{ SE } & \multicolumn{2}{|c|}{$95 \%$ confidence interval } \\
\hline & & & $\mathrm{BCa}$ & $\mathrm{Cl}$ \\
\hline IRD — Positive future social expectations — Intention to rebel & 0.01 & 0.01 & $<0.01$ & 0.02 \\
\hline IRD — Negative future social expectations — Intention to rebel & $0.17^{* * *}$ & 0.02 & 0.13 & 0.21 \\
\hline IRD — Interpersonal distrust — Intention to rebel & $0.11^{* * *}$ & 0.02 & 0.07 & 0.15 \\
\hline IRD — Positive future social expectations — Interpersonal distrust & -0.01 & 0.01 & -0.02 & 0.01 \\
\hline IRD — Negative future social expectations — Interpersonal distrust & $0.18^{* * *}$ & 0.03 & 0.13 & 0.23 \\
\hline Positive future social expectations — Interpersonal distrust — Intention to rebel & 0.01 & 0.01 & -0.01 & 0.02 \\
\hline Negative future social expectations - Interpersonal distrust — Intention to rebel & $0.07^{* * *}$ & 0.02 & 0.04 & 0.10 \\
\hline IRD - Positive future social expectations - Interpersonal distrust — Intention to rebel & $<-0.01$ & $<0.01$ & -0.01 & $<0.01$ \\
\hline IRD — Negative future social expectations — Interpersonal distrust — Intention to rebel & $0.04^{* * *}$ & 0.01 & 0.02 & 0.06 \\
\hline
\end{tabular}

exert a significant mediating effect on the relationship between IRD and intention to rebel; therefore, the results provided partial support for the fourth hypothesis.

The results showed significant correlations between the five variables examined in this study. Of these, intention to rebel was significantly positively correlated with IRD. That is, the likelihood that individuals will participate in rebellion will rise if they experience high levels of IRD, a finding consistent with relative deprivation theory (Crosby, 1976; Gurr, 1970; Walker \& Pettigrew, 1984), where IRD increased collective behaviour. There is literature that suggests that the egoistically deprived individual may externalise their suffering and turn against those who have power in order to improve their situation (Schmitt et al., 2010); other scholars have likewise suggested that IRD can influence group-level outcomes (Smith et al., 2012), such as intention and action to cooperate (Zhang et al., 2016), protest (Schmitt et al., 2010), and collective action (Zhang et al., 2010). Thus, if RD is reduced via appropriate treatment, the incidence of rebellion is also likely to decrease. How this occurs is a question out of the range of this research, and we expect that psychologists, sociologists, and political scientists may work together to find ways to reduce IRD in specific social contexts.

The results also showed that IRD influenced intention to rebel via the mediating role of negative future social expectations. A number of researchers have posited that the relationship between attitude and behaviour is very strong (Mishra \& Novakowski, 2016; Upmeyer, 1990); that is, that behaviour is an expression of attitudes, and future social expectations - attitudes about the future of society - are not only affected by emotions and the external environment but in turn inevitably affect psychological status and behaviour. When individuals who experience high levels of IRD are pessimistic about the future of society and are influenced by negative emotions, such as resentment and anger, they tend to exhibit stronger intention to rebel. In this regard, the current results are consistent with those of previous studies (Caskell \& Smith, 1984; Nurmi, 1991) and provide empirical support for the theory of RD (Bernstein \& Crosby, 1980; Smith \& Huo, 2014) in which IRD has a negative effect on future expectations, resulting in unconventional behaviour. Although positive future social expectations were negatively correlated with intention to rebel in the current study, RD did not suppress intention to rebel entirely via positive future social expectations. In other words, high levels of $\mathrm{RD}$ and positive expectations of the future of society were insufficient to eliminate rebellious tendencies. Field theory posits that human behaviour is the product of the interaction between (human) internal and external factors. (Lewin, 1943), and additional cognitive variables and unknown events may change the process of movement from attitudes to behaviours. Fishbein and Ajzen (2010) also report that people who appeared to hold positive attitudes toward one behaviour rarely engaged in this behaviour. Therefore, additional variables should be explored to clarify this mechanism in future research.

IRD also predicted intention to rebel indirectly via interpersonal distrust. Previous research has shown that economic inequality leads to a sense of injustice and destroys interpersonal distrust (Bernstein \& Crosby, 1980; Smith et al., 2012; Uslaner, 2013). On the other hand, Giddens' duality of structure can be used as theoretical support: distrust as a psychological inducement can affect the individual's subjective choice and produce extreme anxiety and anger, which eventually leads to violent behaviour; the rebellion itself then becomes an influencing factor and alters feelings of trust and behavioural choices, creating a vicious cycle of distrust and violence (Giddens, 1998; Rodriguez, Dibello, Øverup, \& Neighbors, 2015). Moreover, Schul and Peri (2015) also report that trust exerted an impact on individuals' behavioural decisions.

In addition, negative future social expectations exerted a significant influence on the establishment of interpersonal distrust and indirectly increased intention to rebel; however, positive future social expectations did not have this effect. From one perspective, if individuals foresee considerable risk in the future, this results in negative assessment of the future society, reducing the individual's sense of security and affecting the establishment of trust in society. This finding is consistent with those of previous studies (Featherman \& Pavlou, 2003; Zhang \& Bond, 
1993). From another perspective, some studies have indicated that although Chinese people were convinced that the main reason for the increasing gap between rich and poor people was social injustice, they also considered this situation to be relatively fair and believed that diligence, striving, and talent were the main factors affecting material satisfaction (Whyte, 2010). When individuals in the reform era believe that their efforts will be successful, they rely on and believe in themselves rather than others in society, which could explain the finding that interpersonal distrust did not exert a significant mediating effect on positive future social expectations in this study. This suggests that intervention could alter individuals' attitudes toward the future of society by reducing negative future social expectations and enhancing interpersonal trust, to promote the optimisation of individual adaptation behaviour.

\section{Implications}

This study applied psychological perspectives and methodology to examine RD. To our knowledge, it was the first study to explore the mechanisms underlying IRD, future social expectations, interpersonal distrust, and intention to rebel and to develop a future social expectations and interpersonal distrust model involving the multiple mediation of IRD and intention to rebel. The establishment and examination of the model not only validated previous theoretical analysis of IRD in group events, collective behaviour and, in particular, group crimes, but also revealed additional factors that affect the relationship between future social expectations (particularly those of a negative nature) and interpersonal distrust. Therefore, the study findings provide a theoretical and empirical foundation for the development of strategies to reduce collective behaviour in China in the reform era. In addition, the study sample included multiple classes and groups, which provides a solid foundation for the universality and promotion of the research.

\section{Limitations and Future Directions}

The study was subject to some limitations. Most notably, the data in the study were cross-sectional and correlational. Hence, causal direction of any effects between variables in the study cannot be confirmed and any hypothesised causal directions are purely speculative. It would be beneficial to explore how related variables change over time and in relation to each other. Further, including observational methods in future analyses would likely deepen our understanding of the interaction of related variables and provide empirical evidence to prevent collective behaviour. In addition, most of the questionnaires used in the study were one-dimensional measurement instruments. This limited our insight into the differences between internal variables and the effects of variables other than those included in the study. As far as research tools are concerned, it is necessary to establish measurement tools that involve all dimensions and higher reliability in future research. Furthermore, only self-report questionnaires were used to collect data here; as such, the results presented in this study likely underestimate or overplay the relationships between IRD and intention to rebel. Therefore, a combination of different methods, such as experimental research or third-party assessments, should be used in future studies.

\section{Conclusion}

The findings indicated that IRD predicted intention to rebel directly and indirectly via negative future social expectations, interpersonal distrust, and the chain mediating effect of negative future social expectations and interpersonal distrust. Therefore, negative future social expectations and interpersonal distrust are important factors that influence intention to rebel. In view of this, research should not only focus on the direct influence of RD on intention to rebel but also emphasise the indirect impact that occurs via negative future social expectations and interpersonal distrust.

\section{Acknowledgments}

We sincerely appreciate Professor James Liu and anonymous reviewers for their comments. This work was supported by the National Social Science Foundation of China (14BSH071); the MOE (Ministry of Education in China) Project of Humanities and Social Sciences (16YJCZH105); and the Graduate Student Innovation Project of Jiangxi Normal University (YC2017-S167).

\section{References}

Ajzen, I. (1985). From intentions to actions: A theory of planned behavior. Advances in Experimental Social Psychology, 20, 163.

Alesina, A., \& Ferrara, E.L. (2002). Who trusts others? Journal of Public Economics, 85, 207-234.

Anderson, L.R., Mellor, J.M., \& Milyo, J. (2005). An experimental study of the effects of inequality and relative deprivation on trusting behavior (Working Paper no. 14). Williamsburg, VA: College of William and Mary.

Atkinson, J.W., \& Cartwright, D. (1964). Some neglected variables in contemporary conceptions of decision and performance. Psychological Reports, 14, 575-590.

Bar-Tal, D., Raviv, A., Shapira, P., \& Kahn, D.T. (2016). Lay psychology of trust/distrust and beyond in the context of an intractable conflict: The case of Israeli Jews. In I. Alon \& D. Bar-Tal (Eds.), The role of trust in conflict resolution (pp. 197-213). Cham, Switzerland: Springer International Publishing.

Bernstein, M., \& Crosby, F. (1980). An empirical examination of relative deprivation theory. Journal of Experimental Social Psychology, 16, 442-456.

Birt, C.M., \& Dion, K.L. (1987). Relative deprivation theory and responses to discrimination in a gay male and lesbian sample. British Journal of Social Psychology, 26, 139. 
Brockner, J. (1996). Understanding the interaction between procedural and distributive justice: The role of trust. In R.M. Kramer \& T.R. Tyler (Eds.), Trust in organizations: Frontiers of theory and research (pp. 390-413). Thousand Oaks, CA: Sage Publications.

Brockmann, H., Delhey, J., Welzel, C., \& Yuan, H. (2009). The China puzzle: Falling happiness in a rising economy. Journal of Happiness Studies, 10, 387-405.

Callan, M.J., Shead, N.W., \& Olson, J.M. (2011). Personal relative deprivation, delay discounting, and gambling. Journal of Personality \& Social Psychology, 101, 955-73.

Carmi, N., \& Arnon, S. (2014). The role of future orientation in environmental behavior: Analyzing the relationship on the individual and cultural levels. Society \& Natural Resources, 27, 1304-1320.

Caskell, G., \& Smith, P. (1984). Relative deprivation in black and white youth: An empirical investigation. British Journal of Social Psychology, 2, 121-131.

Catherall, D.R. (1991). Aggression and projective identification in the treatment of victims. Psychotherapy Theory Research \& Practice, 28, 145-149.

Cho, J. (2006). The mechanism of trust and distrust formation and their relational outcomes. Journal of Retailing, 82, 25-35.

Cohen-Chen, S., Halperin, E., Crisp, R.J., \& Gross, J.J. (2013). Hope in the Middle East: Malleability beliefs, hope, and the willingness to compromise for peace. Social Psychological \& Personality Science, 5, 67-75.

Coleman, J. (1990). Foundations of social theory. Cambridge, MA: The Belknap Press of Harvard University Press.

Crosby, F. (1976). A model of egoistical relative deprivation. Psychological Review, 83, 85-113.

Crosby, F. (1979). Relative deprivation revisited: A response to miller, bolce, and halligan. American Political Science Review, 73, 103-112.

Featherman, M.S., \& Pavlou, P.A. (2003). Predicting e-services adoption: A perceived risk facets perspective. International Journal of Human-Computer Studies, 59, 451-474.

Feldman, D.C., Leana, C.R., \& Bolino, M.C. (2002). Underemployment and relative deprivation among re-employed executives. Journal of Occupational \& Organizational Psychology, $75,453-471$.

Fishbein, M., \& Ajzen, I. (2010). Predicting and changing behavior: The reasoned action approach. New York, NY: Psychology Press.

Folger, R. (1986). A referent cognitions theory of relative deprivation. In J.M. Olson, C.P. Herman, \& M.P. Zanna (Eds.), Relative deprivation and social comparison: The Ontario symposium (vol. 4, pp. 33-55). Hillsdale, NJ: Lawrence Erlbaum Associates.

Fukuyama, F. (1995). Social capital and the global economy. Foreign Affairs, 74, 89-103.

Giddens, A. (1984). The constitution of society. Rationality \& Society, 30, 405-428.

Giddens, A. (1998). Risk society: The context of British politics. In J. Franklin (Ed.), The politics of risk society (p. 23). Cambridge, UK: Polity Press.
Greitemeyer, T., \& Sagioglou, C. (2017). Increasing wealth inequality may increase interpersonal hostility: The relationship between personal relative deprivation and aggression. Journal of Social Psychology, 157, 766-776.

Guimond, S., \& Dubésimard, L. (1983). Relative deprivation theory and the Quebec nationalist movement: The cognitionemotion distinction and the personal-group deprivation issue. Journal of Personality \& Social Psychology, 44, 526-535.

Gurr, T.R. (1970). Why men rebel. Princeton, NJ: Princeton University Press.

Ishida, A. (2014). Income inequality and relative deprivation: A formal theoretic view. XVIII ISA World Congress of Sociology.

Jost, J.T., Chaikalis-Petritsis, V., Abrams, D., Sidanius, J., van der Toom, J., \& Bratt, C. (2012). Why men (and women) do and don't rebel: Effects of system justification on willingness to protest. Personality \& Social Psychology Bulletin, 38, 197-208.

Kasperson, R.E., Golding, D., \& Tuler, S. (1992). Social distrust as a factor in siting hazardous facilities and communicating risks. Journal of Social Issues, 48, 161-187.

Kinard, E.M. (1980). Emotional development in physically abused children. American Journal of Orthopsychiatry, 50, 686-696.

Kinard, E.M. (1982). Aggression in abused children: Differential responses to the rosenzweig picture-frustration study. Journal of Personality Assessment, 46, 139-141.

Kurzman, C. (2003). Review of the book Why Muslims rebel: Repression and resistance in the Islamic world, by Mohammed M. Hafez. Social Forces, 82, 863-865.

Lerner, M.J., \& Miller, D.T. (1978). Just world research and the attribution process: Looking back and ahead. Psychological Bulletin, 85, 1030-1051.

Lewin, K. (1943). Defining the 'Field at a given time'. Psychological Review, 50, 292-310.

Ma, A. (2012). Relative deprivation and social adaption: The role of mediator and moderator. Acta Psychologica Sinica, 44(3), 377-387.

MacKinnon, D. (2000). Contrasts in multiple mediator models. In J. Rose, L. Chassin, C. Presson, \& S. Sherman (Eds.), Multivariate applications in substance use research (pp. 141160). Mahwah, NJ: Erlbaum.

Malti, T., Averdijk, M., Ribeaud, D., Rotenberg, K.J., \& Eisner, M.P. (2013). 'Do you trust him?' Children's trust beliefs and developmental trajectories of aggressive behavior in an ethnically diverse sample. Journal of Abnormal Child Psychology, 41, 445-456.

Mathye, L.V. (2009). Therapeutic techniques for treatment of adolescents with rebellious behavior. Unpublished doctoral thesis, University of South Africa, Pretoria.

Merton, R.K. (1949). Social structure and anomie: Revisions and extensions. In R.N. Anshen (Ed.), The family: Its function and destiny (pp. 226-257). Oxford, England: Harper.

Mishra, S., \& Novakowski, D. (2016). Personal relative deprivation and risk: An examination of individual differences in personality, attitudes, and behavioral outcomes. Personality \& Individual Differences, 90, 22-26. 
Napoletano, A., Elgar, F.J., Saul, G., Dirks, M., \& Craig, W. (2016). The view from the bottom: Relative deprivation and bullying victimization in canadian adolescents. Journal of Interpersonal Violence, 31, 3443-3463.

Neckerman, K.M., \& Torche, F. (2007). Inequality: Causes and consequences. Annual Review of Sociology, 33, 335-357.

Nurmi, J.E. (1991). How do adolescents see their future? A review of the development of future orientation and planning. Developmental Review, 11, 1-59.

Offer, D. (1971). Rebellion and anti-social behavior. American Journal of Psychoanalysis, 31, 13-19.

Osborne, D., Smith, H.J., \& Huo, Y.J. (2012). More than a feeling: Discrete emotions mediate the relationship between relative deprivation and reactions to workplace furloughs. Personality and Social Psychology Bulletin, 38, 628-641.

Paxton, P. (2002). Social capital and democracy: An interdependent relationship. American Sociological Review, 67, 254-277.

Pettigrew, T.F. (1978). Three issues in ethnicity: Boundaries, deprivations, and perceptions. In J.M. Yinger \& S.J. Cutler (Eds.), Major social issues: A multidisciplinary view (pp. 25-49). New York, NY: Free Press.

Pires, B. (2014). When people rebel: A computational approach to violent collective action (Doctoral dissertation). Retrieved from http://hdl.handle.net/1920/8973

Preacher, K., \& Hayes, A. (2008). Asymptotic and resampling strategies for assessing and comparing indirect effects in multiple mediator models. Behavior Research Methods, 40, 879-891.

Rodriguez, L.M., Dibello, A.M., Øverup, C.S., \& Neighbors, C. (2015). The price of distrust: Trust, anxious attachment, jealousy, and partner abuse. Partner Abuse, 6, 298-319.

Rotter, J.B. (1971). Generalized expectancies for interpersonal trust. American Psychologist, 26, 443-452.

Rowlingson, K. (2011). Does income inequality cause health and social problems? New York: Joseph Rowntree Foundation. Retrieved from http://www.jrf.org.uk/sites/files/jrf/ inequality-income-socialproblems-full.pdf

Rözer, J.J., \& Volker, B. (2016). Does income inequality have lasting effects on health and trust? Social Science \& Medicine, $149,37-45$.

Runciman, W.G. (1966). Relative deprivation and social justice: A study of attitudes to social inequality in twentieth century Britain. Aldershot, UK: Gregg Revivals.

Schmitt, M., Maes, J., \& Widaman, K. (2010). Longitudinal effects of egoistic and fraternal relative deprivation on wellbeing and protest. International Journal of Psychology Journal International De Psychologie, 45, 122-130.

Scholz, J.T., \& Lubell, M. (1998). Trust and taxpaying: Testing the heuristic approach to collective action. American Journal of Political Science, 42, 398-417.

Schul, Y., \& Peri, N. (2015). Influences of distrust (and trust) on decision making. Social Cognition, 33, 414-435.

Schweer, M., \& Siebertz-Reckzeh, K. (2014). Personal, systemic and transsystemic trust: Individual and collective resources for coping with societal challenges. Mindful change in times of permanent reorganization. Heidelberg: Springer Berlin Heidelberg.

Shoham, S.G., Knepper, P., \& Kett, M. (2010). International handbook of criminology (pp. 163-169). Boca Raton, FL: CRC Press.

Shrout, P.E., \& Bolger, N. (2002). Mediation in experimental and non-experimental studies: New procedures and recommendations. Psychological Methods, 7, 422-445.

Smith, H.J., \& Huo, Y.J. (2014). Relative deprivation: How subjective experiences of inequality influence social behavior and health. Policy Insights from the Behavioral \& Brain Sciences, $1,231-238$.

Smith, H.J., Pettigrew, T.F., Pippin, G.M., \& Bialosiewicz, S. (2012). Relative deprivation a theoretical and meta-analytic review. Personality and Social Psychology Review, 16, 203232.

Stouffer, S.A., Suchman, E.A., Devinney, L.C., Star, S.A., \& Williams, R.M. (1949). The American soldier: Adjustment during army life (vol. 1). Princeton, NJ: Princeton University Press.

Sun, D., \& Guo, Y. (2016). Relative deprivation: Wanting, deserving, resentment for not having. Journal of Psychological Science, 39, 714-719

Sutton, R.M., \& Winnard, E.J. (2007). Looking ahead through lenses of justice: The relevance of just-world beliefs to intentions and confidence in the future. British Journal of Social Psychology, 46, 649-666.

Sztompka, P. (1999). Trust: A sociological theory. Cambridge, UK: Cambridge University Press.

Tatarko, A. (2014). Trust, cooperative behavior and economic success: When trust is the capital of the person? Hse Working Papers.

Teng, G., Jin, S., \& Liu, H. (2016). Effect of social just expectation on interpersonal trust among college students: Mediating role of positive belief. Journal of Dalian University of Technology, 37, 22-25.

Toizer, B. (2016). Perceived essentialism, group relative deprivation, and collective action. Unpublished doctoral dissertation, Oberlin College, $\mathrm{OH}$.

Upmeyer, A. (Ed.). (1990). Attitudes and behavioral decisions. New York, NY: Springer Verlag.

Uslaner, E.M. (2002). Religion and civic engagement in Canada and the United States. Journal for the Scientific Study of Religion, 41, 239-254.

Uslaner, E.M. (2010). Social capital, television, and the 'mean world': Trust, optimism, and civic participation. Political Psychology, 19, 441-467.

Uslaner, E.M. (2013). Trust as an alternative to risk. Public Choice, $157,629-639$.

Vanneman, R.D., \& Pettigrew, T.F. (1972). Race and relative deprivation in the urban united states. Race, 13, 461486.

Van Vugt, M., \& Van Lange, P.A.M. (2006). The altruism puzzle: Psychological adaptations for prosocial behavior. In M. Schaller, J.A. Simpson, \& D.T. Kenrick (Eds.), Evolution 
and social psychology (pp. 237-261). Madison, CT: Psychosocial Press.

Vold, G.B., Bernard, T.J., \& Snipes, J.B. (2005). Theoretical criminology. New York, NY: Oxford Universiy Press.

Walker, I., \& Pettigrew, T.F. (1984). Relative deprivation theory: an overview and conceptual critique. British Journal of Social Psychology, 23(4), 301-310.

Whyte, M.K. (2010). Fair versus unfair: How do Chinese citizens view current inequalities? In J.C. Oi, S. Rozelle, \& X. Zhou (Eds.), Growing pains: Tensions and opportunity in China's transformation (pp. 305-332). Stanford, CA: Shorenstein Center.

Wilkinson, R.G., \& Pickett, K.E. (2007). The problems of relative deprivation: Why some societies do better than others. Social Science of Medicine, 65, 19651978.

Wilkinson, R.G., \& Pickett, K.E. (2009). Income inequality and social dysfunction. Annual Review of Sociology, 35, 493-511.

Wright, S.C., Taylor, D.M., \& Moghaddam, F.M. (1990). The relationship of perceptions and emotions to behavior in the face of collective inequality. Social Justice Research, 4, 229250.

Xiong, M., \& Ye, Y.D. (2016). The concept, measurement, influencing factors and effects of relative deprivation. Advances in Psychological Science, 24, 438-453.

Zhang, H., Liu, M., \& Tian, Y. (2016). Individual-based relative deprivation (IRD) decreases prosocial behaviors. Motivation \& Emotion, 40, 1-12.

Zhang, J. \& Bond, M.H. (1993). Target-based interpersonal trust: Cross-cultural comparison and its cognitive model. Acta Psychologica Sinica, 25, 54-62.

Zhang, J.P., Guo, Y.F., \& Zhang, N. (2013). Creating a harmonious doctor-patient relationship based on positive psychology. Chinese Medical Ethics, 24, 71-72.

Zhang, S.W., Wang, E.P., \& Zhou, J. (2010). Relative deprivation and relative gratification: The motivation of Chinese mass incidents. Journal of Public Management, 7, 95-102.

Zoogah, D.B. (2010). Why should I be left behind? Employees' perceived relative deprivation and participation in development activities. Journal of Applied Psychology, 95, 159-179. 